Article

\title{
Extruded Solid Biofuels of Rice Straw Plus Oriented Strand Board Residues at Various Proportions
}

\author{
Feiyu Tian, Deliang $\mathrm{Xu}$ and $\mathrm{Xinwu} \mathrm{Xu}$ * \\ College of Materials Science and Engineering, Nanjing Forestry University, Nanjing 210037, China; \\ tianfy9758@163.com (F.T.); xudl@njfu.edu.cn (D.X.) \\ * Correspondence: xucarpenter@njfu.edu.cn; Tel.: +86-25-85412389 or +86-138-1409-7545
}

Received: 1 June 2020; Accepted: 30 June 2020; Published: 4 July 2020

\begin{abstract}
Disposal of vast agricultural residues has been a nerve-wracking social problem in many agriculture-intensive regions. Open-field combustion both squanders those biomass resources and causes severe atmospheric pollution and hazards. In addition, wood industries yield residues such as sanding powders without value application. Production of biofuels out of these biomass provides a multiple beneficial solution. To that end, this work focused on fabrication of biomass fuels using rice straws (Calorific value: $14.7 \mathrm{MJ} / \mathrm{Kg}$ ) and wood residues from OSB industries (Calorific value: 17.3 MJ/Kg). Biofuel sticks from various proportions of biomass residues were made using an $18.5 \mathrm{KW}$ industrial biomass extruder without adding bonding agents, achieving densities of 1.0-1.6 g/ $\mathrm{cm}^{3}$ and comparative calorific values. The biofuel sticks exhibit moisture sensitivity when subjected to a ten-day conditioning. Release of residual stresses that were created during the densification process led to structural destruction of the products under moisture aggression. It's highlighted that combination of rice straw particles with OSB residues gives sound extrusion process ability and high combustibility. The blend of rice straws and OSB residues are proven practically feasible for making solid biofuels. It's suggested to promote the waste-to-wealth technological scheme in addressing the energy crisis worldwide, especially in those regions rich in agricultural residues while poor in non-renewable energy sources.
\end{abstract}

Keywords: biofuel; rice straw; oriented strandboard (OSB)

\section{Introduction}

Energy as well as resources promote the sustainable existence of the Earth and mankind by supporting industrial productions and household consumptions. In a long history, non-renewable energy sources, i.e., coal, oil, and natural gas, account for the backbone of world's energy supplies, which may continue for the foreseeable future. The fast and vast consumption of those sources in constructions, industries, and household utilities has shown an increasing crisis for the next generations without adequate options available [1].

In reducing the global dependency on fossil fuels, renewable bioenergy sources, e.g., agricultural or wood industry residues, may provide flexible alternative solutions [2]. Depending on solar energy, the planet produces tremendous quantities of plant-based bioresources annually, which can supply green bioenergy, e.g., as biofuels. The estimated production capacity of biomaterials on Earth reaches up to $1.1 \times 10^{21}$ tons, which, however, is utilized at a small scale and low technical levels. As an example, the worldwide production of rice straw is approximately $8-10 \times 10^{8}$ tons per year [3]. In China, the annual production of rice and wheat straws reaches about $3-4 \times 10^{8}$ tons, $65 \%$ of which is normally being utilized as so-called " $4 \mathrm{Fs}$ ", i.e., fodder for animals or microorganisms (e.g., mushroom cultivation), fertilizer for plants (still a global challenge considering the long natural decomposition durations), feedstock for industries (e.g., strawboard, pulping, and paper), and fuels (for household 
and industries). The remaining are burnt insitu for nothing but lead to air pollution and greenhouse gases [4,5]. From 2003 to 2013, the crop residue production and its energy potential in the world rose by $1208 \mathrm{MT}$ and 19,328 MBTU, respectively, which equals 487.38 tons of oil [6].

Matsumura et al. [7] investigated the feasibility of using agricultural residues in Japan, mainly rice straw and rice husk, as an energy source. The potential energy quantity is assumed to achieve 3.8 billion $\mathrm{kWh}$ of electricity per year even at a low heat acquisition efficiency rate of $7 \%$. The doubled electricity price, however, hinders the prompt promotion process, which needs both financial incentives and innovated technologies to enable the effective use of agricultural residue abroad. Dhakate et al. converted rice straw into biochar by torrefaction process, which had the calorific value equivalent to that of bituminous coal used in thermal power plants [8].

Bio-residues such as rice straws or wood processing residues are produced in a dispersive manner, unlike concentrated fossil fuels through millenniums of natural deposition process. In that context, biomass densification technology may facilitate the transportation, storage, and handling processes of those raw materials, leading to denser solids (pellets, briquettes, or sticks) with tremendously higher energy intensity. Simultaneously, explosion risks in incineration of some pulverized biofuels, e.g., wood sanding powders, at a closed burning environment may be avoided [9]. Chou et al. fabricated solid fuel briquette from rice straw and bran [10]. They found that the rice bran increased the heat value and decreased the thermo-energy used to compress the briquette. Stasiak et al. investigated the mechanical and combustion properties of pellets made of pine sawdust mixed with wheat and rapeseed straws, disclosing that the mechanical and combustion parameters are proportion-dependent [11]. Yerizam et al. experimented with hybrid biomass briquettes using rice straws and coconut shell residues, resulting in a calorific value of $18.2 \mathrm{MJ} / \mathrm{Kg}$ when two raw residues were added identically [12].

Densified solid biofuels are usually fabricated by compression or extrusion procedures. The physic-mechanical performance of the products is determined by multiple factors like constituents, moisture content, unit size, binders (or not), and densification variables (forming pressure, and pellet mill and roll press variables) $[13,14]$. From a point of avoiding secondary environment pollution, binders normally are omitted. In that case, the morphology and moisture contents of the constituents, and the processing variables should be cautiously chosen so as to acquire adequately strong and durable densified products.

In this work, densified biofuel sticks were fabricated using rice straws and oriented strandboard (OSB) residues without any bonding agents. Various shapes, sizes, and combinations of raw materials were tried to detect the influences on physical and combustion properties of the products. The main goals of this work are to find alternative sustainable biofuel sources for non-renewable fuels from the rich industrial and agricultural plant fibrous residues.

\section{Materials and Methods}

\subsection{Materials}

Four plant-based materials were used as components of densified biofuels, i.e., screened-out fines (Osf) and sanding powders (Op) of poplar OSB, rice straw particles (Rp), and rice strawboard sanding powders (Rs). The above materials are used as industrial fuels in OSB or strawboard plants as partial replacements of coal, except rice straw particles, which were hammer-milled units for manufacturing strawboard (Dingyuan, China). Moistures of the four units were in the range of $6.4-9.9 \%$.

The size distributions of the four units by sieve analysis are shown in Figure 1. A lab-scale electrical driven multilayer sieve was used to sort the four plant-based materials. For each test, $10 \mathrm{~g}$ of materials were randomly chosen and screened. It is seen that sanding powders (i.e., Rs and Op) exhibit evidently smaller sizes than other samples. Hammer-milled rice straw particles (Rp) include both higher contents of super-large units (coarser than $20 \mathrm{mesh} / \mathrm{in}$ or $0.83 \mathrm{~mm}$, accounting for $21.3 \%$ ) 
and fines (more slender than $100 \mathrm{mesh} / \mathrm{in}$ or $0.15 \mathrm{~mm}$, accounting for $41.4 \%$ ). Osf shows size distribution with $40-80 \mathrm{mesh} / \mathrm{in}$ (or $0.18-0.38 \mathrm{~mm}$ ) as the main composition.

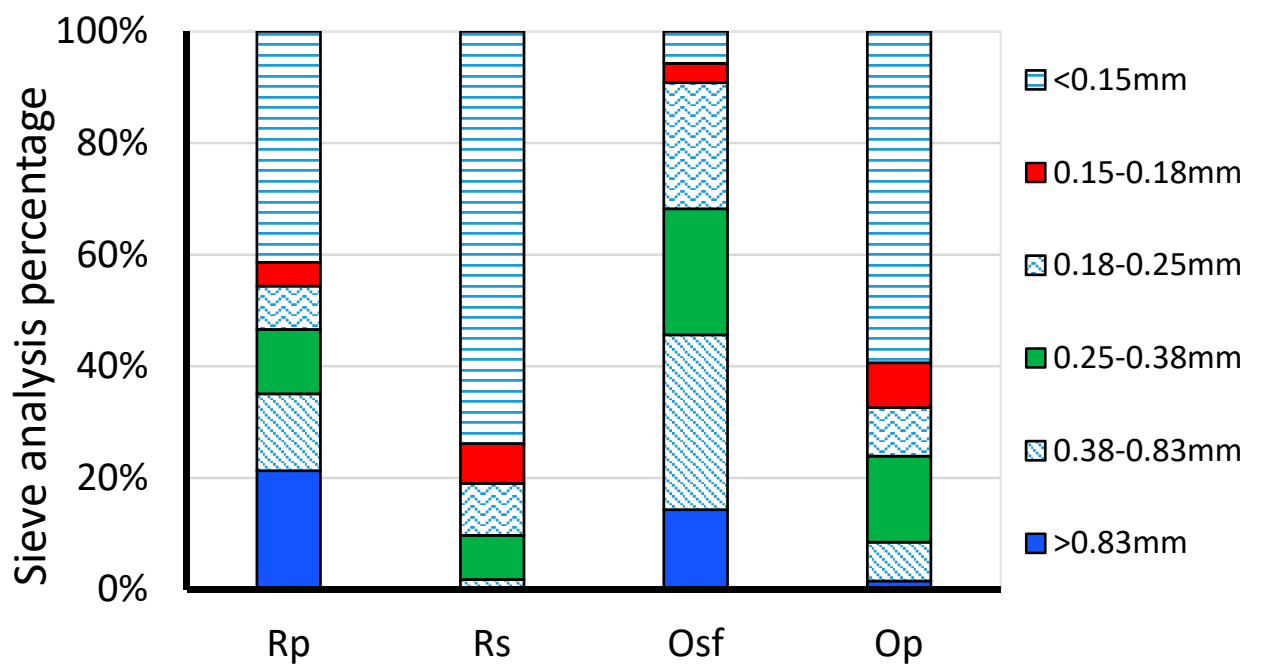

Figure 1. Particle size distributions of various materials. Rp—rice straw particles; Rs —rice strawboard sanding powders; Osf-oriented strandboard (OSB)screened-out fines; Op-OSB sanding powders.

\subsection{Methods}

\subsubsection{Preparation of the Solid Biofuels}

The four different plant-sourced residues were separately or combinedly (Table 1) extruded into stick-shaped solid biofuels with a regular hexagonal appearance and a $20 \mathrm{~mm}$-diameter hollow core (Figure 2), using an industrial biomass fuel extruder (Gongyi Machinery, Henan, China).The power of the extruder motor is $18.5 \mathrm{KW}$, leading to an energy consumption of 230 260 $\mathrm{kWh}$ for preparing one-ton sticks. Extrusion speed was controlled at $1 \mathrm{~m} / \mathrm{min}$ at a work temperature of $300^{\circ} \mathrm{C}$. The hollow core of the biofuel stick is designed essentially to release the gases instantly during the extrusion, in avoidance of voids in or collapse of the extruded products. As well, the hollow core is beneficial for ready incineration of the solidified biofuel sticks. In the above extrusion process, no additives like glues were blended, aiming for a "green" fuel product. Hence, high level densification is needed, which can be shown in the coming text. From Figure 2, the hexagon-profiled sticks show carbonized surfaces, while the inner materials were highly solidified without color darkening.

Table 1. Compositions and properties of the biofuel sticks. Op-OSB sanding powders; Osf-OSB screened-out fines; Rp—rice straw particles; Rs—rice strawboard sanding powders.

\begin{tabular}{|c|c|c|c|c|c|c|c|c|c|c|}
\hline \multirow{2}{*}{$\begin{array}{l}\text { Compositions by } \\
\text { Weight }\end{array}$} & \multirow{2}{*}{$\begin{array}{l}\text { Density } \\
\left(\mathrm{g} \cdot \mathrm{cm}^{-3}\right)\end{array}$} & \multirow{2}{*}{$\begin{array}{c}\text { Initial } \\
\text { Moisture (\%) }\end{array}$} & \multirow{2}{*}{$\begin{array}{l}A_{a d} \\
(\%)\end{array}$} & \multirow{2}{*}{$\begin{array}{l}V_{\text {ad }} \\
(\%)\end{array}$} & \multirow{2}{*}{$\begin{array}{c}\mathrm{FC}_{\mathrm{ad}} \\
(\%)\end{array}$} & \multicolumn{2}{|c|}{$\mathbf{R}_{\mathrm{MCI}}\left(\mathbf{h}^{-\mathbf{1}}\right)$} & \multicolumn{3}{|c|}{$R_{b}\left(g \cdot \min ^{-1}\right)$} \\
\hline & & & & & & $a\left(\times 10^{-5}\right)$ & b & $10 \mathrm{~min}$ & $20 \mathrm{~min}$ & $30 \mathrm{~min}$ \\
\hline $100 \%$ Op & 1.27 & 0.35 & 19.01 & 64.61 & 11.40 & -7.0 & 0.04 & 1.18 & 0.06 & 0.05 \\
\hline $100 \%$ Osf & 1.11 & 2.75 & 21.85 & 68.40 & 6.56 & -8.0 & 0.04 & 1.14 & 0.05 & 0.05 \\
\hline $100 \% \mathrm{Rp}$ & 1.00 & 2.17 & 20.58 & 70.04 & 7.54 & -6.0 & 0.04 & 1.11 & 0.04 & 0.03 \\
\hline $100 \%$ Rs & 1.34 & 1.73 & 13.25 & 68.29 & 13.72 & -4.0 & 0.04 & 1.06 & 0.05 & 0.04 \\
\hline $20 \% \mathrm{Rp}+80 \% \mathrm{Rs}$ & 1.23 & 0.32 & 14.90 & 68.53 & 12.49 & -3.0 & 0.04 & 0.67 & 0.06 & 0.05 \\
\hline $50 \% R p+50 \% R s$ & 1.09 & 0.62 & 17.13 & 68.81 & 10.63 & -4.0 & 0.04 & 1.08 & 0.05 & 0.06 \\
\hline $80 \% \mathrm{Rp}+20 \% \mathrm{Rs}$ & 1.46 & 2.73 & 19.36 & 69.08 & 9.45 & -10.0 & 0.07 & 1.04 & 0.07 & 0.06 \\
\hline $20 \% \mathrm{Rp}+80 \%$ Osf & 1.24 & 2.53 & 4.17 & 68.57 & 26.79 & -7.0 & 0.04 & 0.85 & 0.04 & 0.05 \\
\hline $50 \% \mathrm{Rp}+50 \%$ Osf & 1.12 & 0.17 & 10.43 & 68.83 & 19.57 & -7.0 & 0.05 & 1.00 & 0.04 & 0.05 \\
\hline $80 \%$ Rp $+20 \%$ Osf & 1.09 & 2.73 & 16.68 & 69.09 & 12.35 & -9.0 & 0.05 & 1.02 & 0.04 & 0.06 \\
\hline $20 \% \mathrm{Rp}+80 \% \mathrm{Op}$ & 1.56 & 0.90 & 4.32 & 65.54 & 29.67 & -9.0 & 0.05 & 0.75 & 0.04 & 0.05 \\
\hline $50 \% \mathrm{Rp}+50 \% \mathrm{Op}$ & 1.60 & 0.55 & 10.52 & 66.94 & 21.37 & -6.0 & 0.03 & 0.60 & 0.08 & 0.09 \\
\hline $80 \% \mathrm{Rp}+20 \% \mathrm{Op}$ & 1.23 & 0.37 & 16.72 & 68.33 & 13.07 & -5.0 & 0.04 & 0.98 & 0.06 & 0.06 \\
\hline
\end{tabular}

Note: The repetition levels of density, $\mathrm{A}_{\mathrm{ad}}, \mathrm{V}_{\mathrm{ad}}$, and $\mathrm{FC}_{\mathrm{ad}}$ were five. 


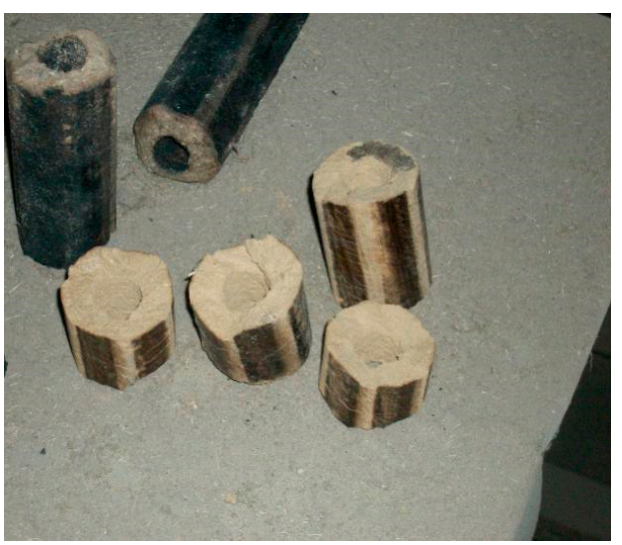

(a)

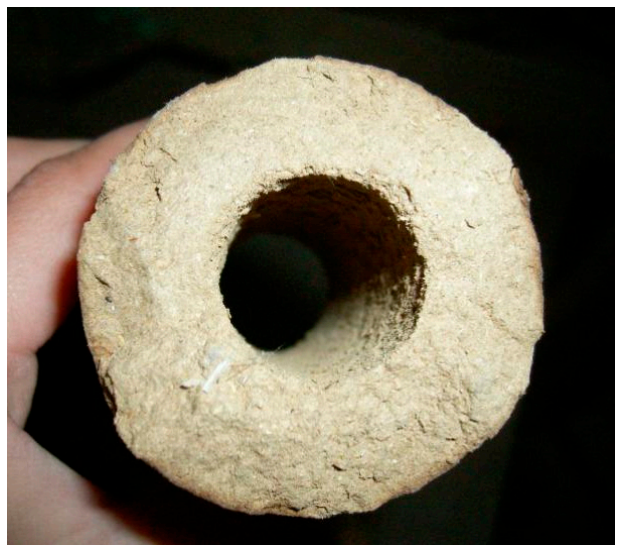

(b)

Figure 2. Exemplified extruded biofuel sticks of OSB residues and/or rice straw, (a) extruded biofuel sticks; (b) cross section.

\subsubsection{Properties Testing}

\section{- Density}

Density of the extruded biofuel sticks was acquired with the water drainage method. Samples cut from the sticks with arbitrary shapes were firstly weighed and were subsequently clothed with a thin film of melted wax. Then the coated sample was immersed in water of an assigned volume. The increased water volume caused by sample immersion is promptly recorded and viewed as the nominal volume of the sample. Ratio of measured weight to volume gives the density value.

\section{- Time-Dependent Conditioning}

Samples cut from the extruded stick-shaped biofuels, $60-80 \mathrm{~g}$ in weight, were conditioned at $20^{\circ} \mathrm{C}$ in a closed glass desiccator. The samples were properly placed on a perforated ceramic holder in such a manner that individual samples could "respire" freely. Humidity in the desiccator was controlled constantly by $1000 \mathrm{~mL}$ of distilled water below the sample holder. The weight of each sample was tested at assigned time intervals. Through a ten-day conditioning, the samples were oven-dried to get the dry mass weight. Accordingly, series of moisture contents were calculated.

- Proximate Analysis

In accordance to the Chinese national standard, Proximate Analysis of Coal (GB/T 212-2008 [15], equivalent to the ISO standards 11,711:1999, 1171:1997 and 562:1998), the incineration-relevant properties of the extruded specimens were tested or calculated.

(1) Ash Content- $\mathrm{A}_{\mathrm{ad}}$

A sample of $(1.0 \pm 0.1) \mathrm{g}$ was closed-burnt in a muffle furnace at $(815 \pm 10)^{\circ} \mathrm{C}$ for $40 \mathrm{~min}$. Repeated the burning process for 20 min twice, avoiding incomplete incineration. Comparison between the final residual weight and the initial sample weight gives the percent ash content, $A_{a d}(\%)$.

(2) Volatile Content- $\mathrm{V}_{\mathrm{ad}}$

A sample of $(1.0 \pm 0.1) \mathrm{g}$ was enclosed in a porcelain crucible and was anaerobically heated in the muffle furnace at $(900 \pm 10){ }^{\circ} \mathrm{C}$ for $7 \mathrm{~min}$. The content of volatile substances, $\mathrm{V}_{\mathrm{ad}}(\%)$, is calculated as:

$$
\mathrm{V}_{\mathrm{ad}}=\frac{\mathrm{M}_{0}-\mathrm{M}_{1}}{\mathrm{M}_{0}} \times 100-\mathrm{M}_{\mathrm{ad}}
$$

where $\mathrm{M}_{0}$ and $\mathrm{M}_{1}$ are sample weight before and after heat treatment $(\mathrm{g})$, and $\mathrm{M}_{\mathrm{ad}}$ is initial moisture content of the sample (\%). 
(3) Content of Fixed Carbon- $-\mathrm{FC}_{\mathrm{ad}}$

Content of fixed carbon, $\mathrm{FC}_{\mathrm{ad}}(\%)$, is calculated as:

$$
\mathrm{FC}_{\mathrm{ad}}=100-\left(\mathrm{M}_{\mathrm{ad}}+\mathrm{A}_{\mathrm{ad}}+\mathrm{V}_{\mathrm{ad}}\right)
$$

- Burning Rate

Burning rate, $R_{b}\left(g \cdot \min ^{-1}\right)$, is defined herein as the weight loss of a tested sample per minute due to the incineration. Samples of equivalent initial weight were closed-burnt in the muffle furnace at $(900 \pm 10){ }^{\circ} \mathrm{C}$ for $10 \mathrm{~min}$ and were instantly weighed. Burning rate, $\mathrm{R}_{\mathrm{b}}\left(\mathrm{g} \cdot \mathrm{min}^{-1}\right)$, is acquired as:

$$
\mathrm{R}_{\mathrm{b}}=\frac{\mathrm{M}_{2}-\mathrm{M}_{3}}{\mathrm{~T}} \times 100
$$

where $\mathrm{M}_{2}$ and $\mathrm{M}_{3}$ are weights of samples before and after $10 \mathrm{~min}$ combustion $(\mathrm{g})$, $\mathrm{T}$ is the corresponding burning time (min). Continue the ten-minute burning process twice to detect the burning rate change in the next combustion durations.

\section{Results}

\subsection{Density}

Density is crucial in determining the mechanical unity of the solidified biofuel sticks in the case that no bonding agents are applied. Later analysis will further disclose that other properties of biofuel sticks are highly dependent on the density. From Table 1, it is seen that all extruded solid biofuels have densities higher than $1.0 \mathrm{~g} / \mathrm{cm}^{3}$. Since the apparent densities of both poplar wood and rice straws $\left(0.3-0.5 \mathrm{~g} / \mathrm{cm}^{3}\right)$ are far lower than $1.0 \mathrm{~g} / \mathrm{cm}^{3}$, all the components must have been subjected to high compaction, with the micro voids (e.g., cell cavities, inter-cellular pores, etc.) eliminated pronouncedly. More information related to the action mechanism and model simulation of the biomass densification process can be referred to in lately published literature [16]. During the mechanical extrusion process, remarked residual stresses are introduced and are transiently entrapped, and may be released with moisture aggression when solidified sticks are subjected to atmospheric exposure. In that context, the entrapped stresses act undesirably as a destroying factor to the solidified sticks.

Density of biofuel sticks is controllable and adjustable by a manner of changing units' shapes, sizes, and proportions. The densest biofuel sticks were those made of combined materials of rice particles and OSB sanding powders, reaching a density level over $1.50 \mathrm{~g} / \mathrm{cm}^{3}$. It seems that the small OSB sanding powders can be perfectly fixed by the fibrous-shaped straw particles, and the hybrid biofuels are more readily shaped. For powder-shaped units (i.e., Rs and Op), higher density levels appear necessary since they have weak inter-locking capability in comparison to the straw particles with larger and slender forms. Strawboard sanding powders, Rs, exhibit the weakest collecting performance, mostly due to the higher content of mineral substances.

\subsection{Time-Dependent Moisture Content}

The borne hydrophilicity of plant-based materials may readily introduce moisture into the extruded biofuels, leading to the gradual loosening and ultimate collapse of the physically-solidified products. All extruded products had a beginning moisture content of $0.32 \%$ to $2.73 \%$ and showed similar moisture increase tendencies along the conditioning process (Figures 3 and 4). In accordance with Figures 3 and 4, the moisture content can be mathematically depicted as a univariate quadratic polynomial function of conditioning time:

$$
\operatorname{IM}(t)=a \cdot t^{2}+b \cdot t+c
$$


where $\operatorname{IM}(t)$ is the increased value of moisture content $(\%), t$ is conditioning time $(h)$, and ' $a$ ', ' $b$ ', ' $c$ ' are constants $\left(\mathrm{h}^{-1}\right)$. In that case, the per hour increase rate of moisture content, $\mathrm{R}_{\mathrm{MCI}}\left(\mathrm{h}^{-1}\right)$, is a linear function of conditioning time:

$$
\mathrm{R}_{\mathrm{MCI}}=\mathrm{a} . \mathrm{t}+\mathrm{b}(\mathrm{a}<0)
$$

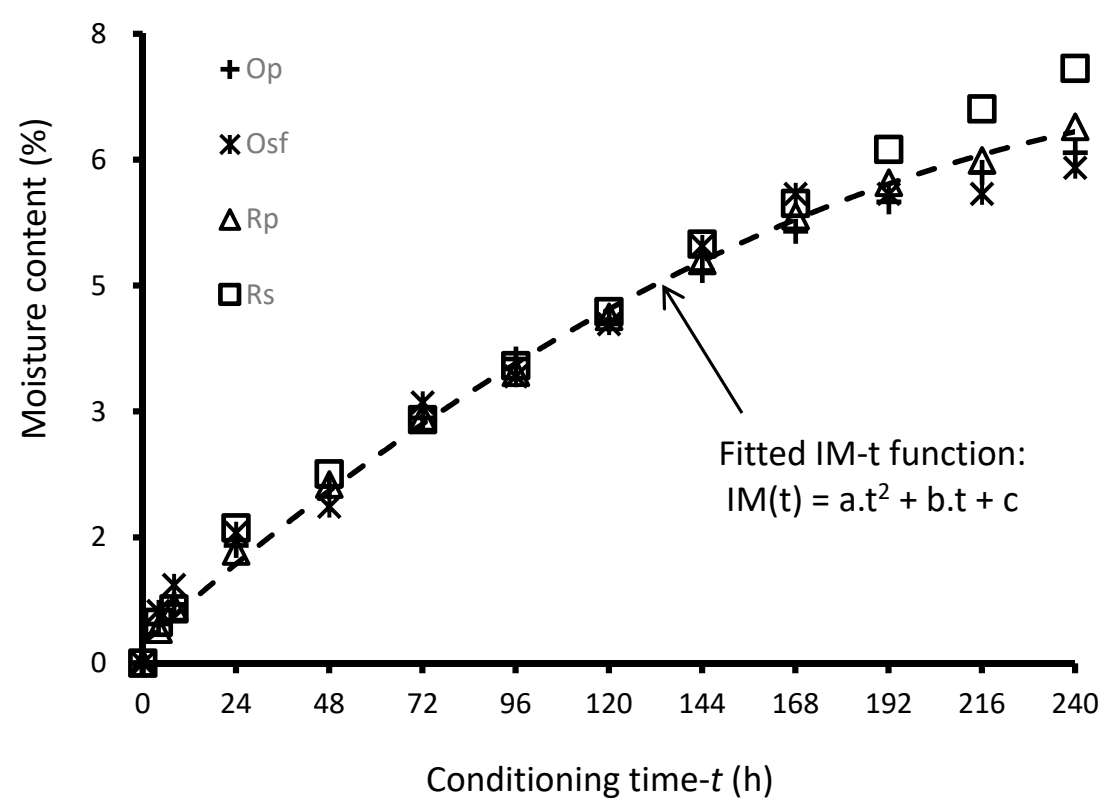

Figure 3. The dependence of moisture content of raw materials on conditioning time.

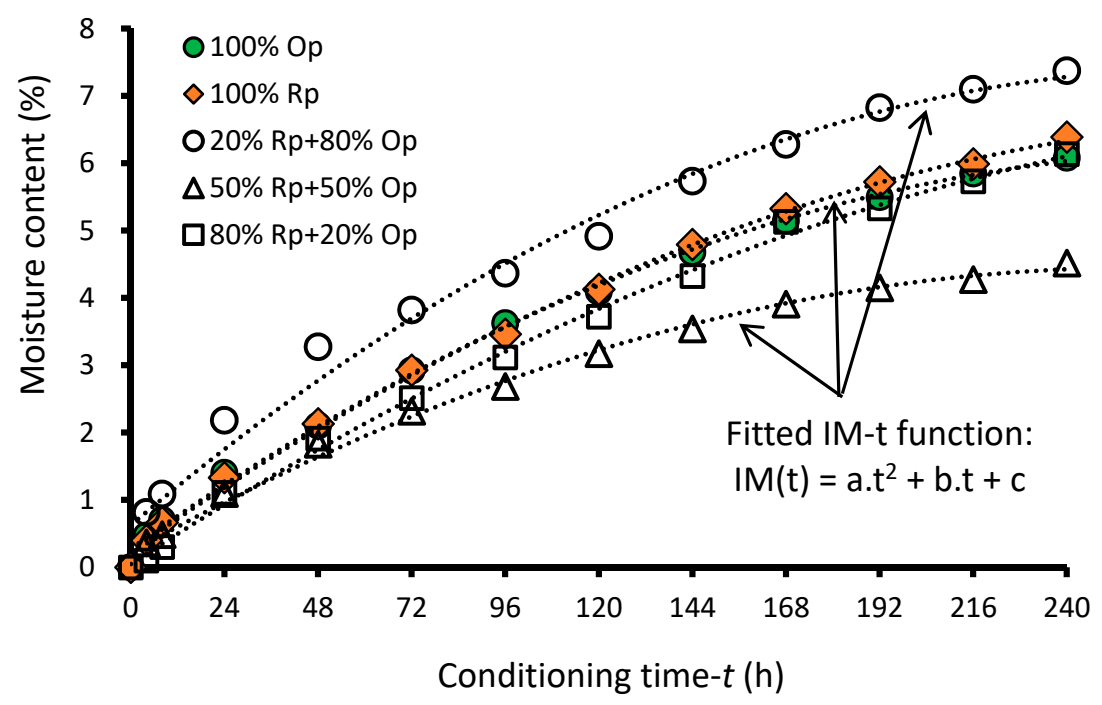

Figure 4. Exemplified relationship between increased moisture content and conditioning time for OSB-straw mixed biofuel sticks (Op plus Rp).

Fitted values of ' $a$ ' and ' $b$ ' parameters were tabulated in Table 1 . It showed that the increase rate of moisture decreased (i.e., a $<0$ ) although the degrees of moisture absorption increased continuously. In response, the IM- $t$ curves extend upwards following a flat-off tendency as conditioning treatment continues. In the end, after ten days of continuous conditioning, all biofuel sticks got swollen and looser, although collapse did not occur due to moisture aggression. Hence, biofuel sticks need cautious storage restricted from moist environments. For instance, a protective package with prominent water-resistance is essential. 


\subsection{Proximate Analysis}

The combustibility and applicability of biofuels are determined by multiple factors including raw materials' attributes and densification variables. Normally, agricultural residues feature higher contents of inorganic mineral components compared to virgin wood [12], which may be improved through open-field leaching after cropping by natural precipitations [17]. It is further noted that the shaped biofuels from both wood and rice straws exhibit much higher levels of incombustible substances $\left(\mathrm{A}_{\mathrm{ad}}\right.$, Table 1$)$ than the raw materials themselves (e.g., normally lower than $4 \%$ for virgin wood). This may be attributed to the higher density levels caused by high-pressure compaction, which significantly hinders the complete incineration of all the materials involved following the standardized testing procedures. Accordingly, the biofuels may produce more ashes than coals and frequent ash-cleaning is essential.

Volatile substances are greatly beneficial in promoting combustion of the fuels with strong flames. From Table 1, volatile contents $\left(\mathrm{V}_{\mathrm{ad}}\right)$ of all extruded biofuels have similar results of $64.61-70.04 \%$, with rice straw particles showing the highest value and OSB sanding powders showing the lowest. The characteristic values are much higher than those of various coals (10-45\%). From this perspective, biomasses are preferably applicable as industrial fuels.

For all the biofuels fabricated herein, the overall contents of combustible substances, i.e., $\mathrm{V}_{\mathrm{ad}}$ plus $\mathrm{FC}_{\mathrm{ad}}$, vary pronouncedly in a broad scope of $76.01-95.36 \%$. This is crucial to determine an optimized option of raw materials. Among the 13 experimented cases (Table 1), an interesting finding lies in the cases of rice straw-wood hybrid biofuels. A combination of OSB residues (sanding powders or screened-out fines) with rice straw particles releases higher $\mathrm{V}_{\mathrm{ad}}$ plus $\mathrm{FC}_{\mathrm{ad}}$ values (81.4-95.36\%) in comparison to the $\mathrm{Rp}+\mathrm{Rs}$ cases $(78.53-81.02 \%)$ or products with a solo unit $(\mathrm{Rp}=74.96, \mathrm{Rs}=77.58 \%$, $\mathrm{Op}=76.01 \%$, or Osf $=80.51 \%$ ). The evidently higher contents of fixed carbon contribute to the higher overall content of combustible substances. This information is valuable. As mentioned above (Section 3.1 "Density"), rice straw particles with OSB powders are readily processed into solid fuels, reaching high densities (which means high energy intensity). The powder-shaped OSB residues act as a "filler" among fiber-shaped straw particles, like the rice bran units in Chou's research [10]. In such a system, rice straws should be controlled at a low percentage (e.g., $20 \%$ in this work).

Other than the intrinsic chemical compositions of rice straw or poplar wood, in this work, the composition of various units and density levels of the extruded products plays important roles as well in changing the proximate analysis results. For example, the content of fixed carbon $\left(\mathrm{FC}_{\mathrm{ad}}\right)$ increases with higher densities of biofuel sticks (Figure 5), which is readily understandable since more biomasses were involved.

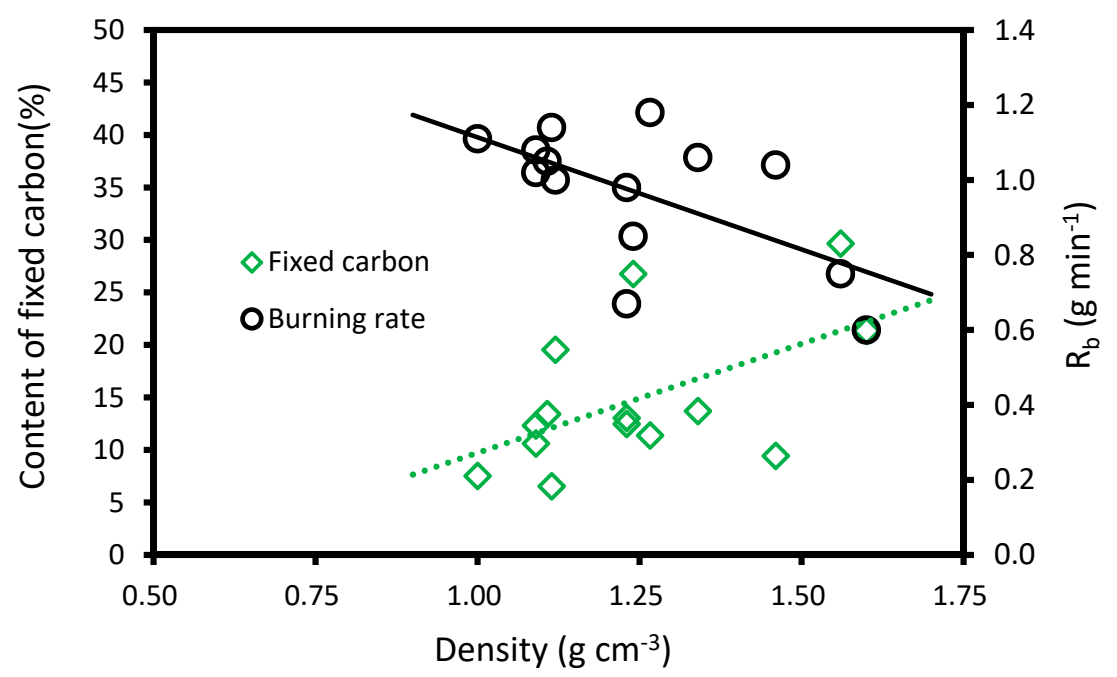

Figure $5 . \mathrm{FC}_{\mathrm{ad}}$ and $\mathrm{R}_{\mathrm{b}}$ as functions of density. 


\subsection{Burning Rate}

Burning rate is inversely correlated to the density of biofuel sticks (Figure 5). Combustion was conducted mainly in the first ten-minute incineration test, the sticks losing weight at a rate of 0.60-1.18 g. $\mathrm{min}^{-1}$ (Table 1). The continuous two burning treatments brought slight weight loss with ignorable $R_{b}$ values of $0.03-0.09 \mathrm{~g} \cdot \mathrm{min}^{-1}$. This means that a feeding period of $10 \mathrm{~min}$ is needed for industrial heat production with solidified bioresources as fuels. To compare, the biofuels with mixed raw materials showed lower burning rates, which may benefit in decreasing feeding frequencies. As well, such a durable and controllable combustion pattern of solidified biofuels completely averts the explosion risks in closed combustion of wood or agricultural residual powders.

\subsection{Calorific Value}

Calorific values of wood or agricultural straws are mainly determined by their contents of carbon (heat value: $32.75 \mathrm{MJ} / \mathrm{Kg}$ ) and hydrogen (heat value: $143 \mathrm{MJ} / \mathrm{Kg}$ ) elements. As for rice straws, carbon and hydrogen account for $44.4 \%$ and $6.2 \%$, respectively. In this case, the theoretical calorific value of rice straws applied in this research was $14.54 \mathrm{MJ} / \mathrm{Kg}$, close to the measured value, $14.7 \mathrm{MJ} / \mathrm{Kg}$. For poplar wood (OSB screened-out fines or sanding powders), the tested value was $17.3 \mathrm{MJ} / \mathrm{Kg}$. Following the mixing rule of composites, hybrid biofuel sticks naturally have calorific values dependent on the compositions. As for a hybrid biofuel stick of 50:50 of rice straws and OSB screened-out fines, it may have an average calorific value of $16 \mathrm{MJ} / \mathrm{Kg}$, equivalent to $54.7 \%$ of that from one kilogram of standardized solid coal. However, once the resource richness and environmental friendliness are considered, biofuels of rice straws and/or OSB residues have strong competency against coal.

\section{Conclusions}

Rice straws and wood industry residues as renewable plant sources have not been valuably applied so far all around the world. In this work, rice straws and OSB residues are proven to be qualified for making solid biofuels using the biomass densification technology, reaching a density level higher than $1.0 \mathrm{~g} / \mathrm{cm}^{3}$ and a comparable calorific value that is accordant with the specific compositions. The physically-solidified products exhibit moisture sensitivity although the high densities help hinder moisture aggression, and the release of residual stresses produced during the densification process may lead to destruction of the products. The combination of rice straw particles and OSB residues is highlighted with ready process ability and high combustibility. A hybrid biofuel stick of 50:50 of rice straws and OSB screened-out fines may have an average calorific value of $16 \mathrm{MJ} / \mathrm{Kg}$, equivalent to $54.7 \%$ of that from one kilogram of standardized solid coal. The waste-to-wealth scheme needs further promotion in addressing the energy crisis worldwide, especially in those regions rich in agricultural residues while poor in non-renewable energy sources. Future works are oriented towards higher production capacities and efficiencies, lower unit-costs, and large-scale applications of this technology.

Author Contributions: The following statements should be used "conceptualization, X.X. and D.X.; methodology, X.X.; software, X.X.; validation, X.X., D.X. and F.T.; formal analysis, X.X.; investigation, D.X.; resources, F.T.; data curation, D.X.; writing —original draft preparation, X.X.; writing-review and editing, X.X.; visualization, F.T.; supervision, D.X.; project administration, X.X.; funding acquisition, D.X.", All authors have read and agreed to the published version of the manuscript.

Funding: This research received no external funding.

Acknowledgments: The research work was financially supported by the National Natural Science Foundation of China (NNSFC) and the Department of Science and Technology of Hubei province.

Conflicts of Interest: The authors declare no conflicts of interest. 


\section{References}

1. Pacheco-Torgal, F.; Cabeza, L.F.; Labrincha, J.; De Magalhães, A. Eco-Efficient Construction and Building Materials; Woodhead Publishing Limited: Sawston, UK, 2014.

2. Lim, J.S.; Manan, Z.A.; Alwi, S.R.W.; Hashim, H. A review on utilisation of biomass from rice industry as a source of renewable energy. Renew. Sustain. Energy Rev. 2012, 16, 3084-3094. [CrossRef]

3. IRRI International Rice Research Institute. Available online: http://irri.org/ourwork/research/valueaddedrice/rice-straw-and-husks/ (accessed on 28 July 2016).

4. Xu, X.; Zhou, D.; Wu, Q.; Vlosky, R.P. Agri-based composites in China: Opportunities and challenges. For. Prod. J. 2004, 54, 8-15.

5. Ahmed, T.; Ahmad, B.; Ahmad, W. Why do farmers burn rice residue? Examining farmers' choices in Punjab, Pakistan. Land Use Policy 2019, 47, 448-458. [CrossRef]

6. Cherubin, M.R.; Oliveira, D.M.S.; Feigl, B.J.; Pimentel, L.G.; Lisboa, I.P.; Gmach, M.R.; Varanda, L.L.; Morais, M.C.; Satiro, L.S.; Popin, G.V.; et al. Crop residue harvest for bioenergy production and its implications on soil functioning and plant growth: A review. Sci. Agric. 2018, 75, 255-272. [CrossRef]

7. Matsumura, Y.; Minowa, T.; Yamamoto, H. Amount, availability, and potential use of rice straw (agricultural residue) biomass as an energy resource in Japan. Biomass Bioenergy 2005, 29, 347-354. [CrossRef]

8. Dhakate, S.R.; Pathak, A.K.; Jain, P.; Singh, M.; Singh, B.P.; Subhedar, K.M.; Sharda, S.S.; Seth, R.K. Rice straw biomass to high energy yield biocoal by torrefaction: Indian perspective. Curr. Sci. 2019, 116, 831-838. [CrossRef]

9. Sun, J. A Preliminary study on the path of pulverized wood dust firing. J. Nanjing For. Univ. 1997, $21,56-62$.

10. Chou, C.S.; Lin, S.H.; Lu, W.C. Preparation and characterization of solid biomass fuel made from rice straw and rice bran. Fuel Process. Technol. 2009, 90, 980-987. [CrossRef]

11. Stasiak, M.; Molenda, M.; Bańda, M.; Wiącek, J.; Parafiniuk, P.; Gondek, E. Mechanical and combustion properties of sawdust-Straw pellets blended in different proportions. Fuel Process. Technol. 2017, 156, 366-375. [CrossRef]

12. Yerizam, M.; Marsi, M.; Novia, N. Characteristics of Composite Rice Straw and Coconut Shell as Biomass Energy Resources (Briquette) (Case study: MuaraTelang Village, Banyuasin of South Sumatra). Int. J. Adv. Sci. Eng. Inf. Technol. 2013, 3. [CrossRef]

13. Mani, S.; Tabil, L.G.; Sokhansanj, S. Effects of compressive force, particle size and moisture content on mechanical properties of biomass pellets from grasses. Biomass Bioenergy 2006, 30, 648-654. [CrossRef]

14. Kaliyan, N.; Morey, R.V. Factors affecting strength and durability of densified biomass products. Biomass Bioenergy 2009, 33, 337-359. [CrossRef]

15. Proximate Analysis of Coal (GB/T 212); China National Coal Standardization Technology Committee Standards Press of China: Beijing, China, 2008. (In Chinese)

16. Xu, G.; Wang, S.; Yu, S.; Zhou, G.; Wang, C.; Wei, H.; Wang, C. Progress in finite element analysis of solidification forming of biomass materials. J. Chongqing Univ. Technol. Nat. Sci. 2020, 34, 205-218. (In Chinese) [CrossRef]

17. Bakker, R.R.; Jenkins, B.M. Feasibility of collecting naturally leached rice straw for thermal conversion. Biomass Bioenergy 2003, 25, 597-614. [CrossRef]

(C) 2020 by the authors. Licensee MDPI, Basel, Switzerland. This article is an open access article distributed under the terms and conditions of the Creative Commons Attribution (CC BY) license (http://creativecommons.org/licenses/by/4.0/). 